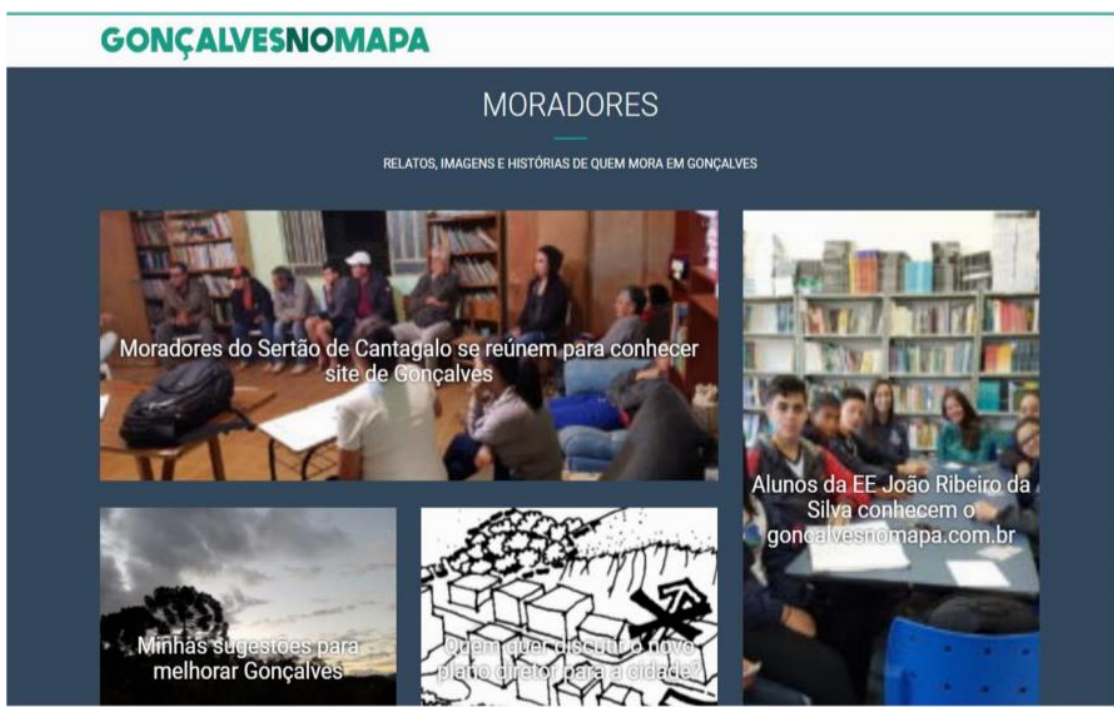

\title{
Um site como ferramenta de identificação de uma agenda pública em uma pequena cidade
}

A website as a tool for identifying a public agenda in a small city

$$
\begin{array}{r}
\text { Magaly Prado }^{1} \\
\text { https://orcid.org/0000-0003-2792-0264 } \\
\text { Adrian Alexandri }{ }^{2} \\
\text { https://orcid.org/0000-0001-7020-9342 }
\end{array}
$$

\section{Resumo}

Sem meios de comunicação locais estruturados, como uma cidade pode ser informada sobre seus principais problemas? O desafio em criar uma plataforma digital jornalística para Gonçalves (Minas Gerais), passa pela estratégia de engajar seus moradores no uso das ferramentas no intuito de discutir e apontar soluções relativas as principais questões identificadas por eles. Em uma pesquisa com dez lideranças da região - à luz de conceitos de agenda pública, engajamento e laços sociais - discutiu-se como se dá a comunicação e quais são os temas prioritários para a cidade. A partir dos resultados, de que modo a prática do jornalismo hiperlocal pode dar visibilidade a um futuro agendamento e o consequente envolvimento nos debates para melhoria daquilo que é mais urgente?

Palavras-chave: Agenda pública; Jornalismo hiperlocal; Engajamento; Ferramentas.

\begin{abstract}
Without structured local media, how can a city be informed about its main problems? The challenge of creating a digital journalistic platform for Gonçalves (Minas Gerais) involves the strategy of engaging its residents in the use of tools in order to discuss and identify solutions related to the main issues identified by them. In a research with ten leaders of the region - in the light of concepts of public agenda, engagement and social ties - we discussed how communication occurs and what are the priority themes for the city. From the results, in what way the practice of hyperlocal journalism can give visibility to a future schedule and the consequent involvement in the debates to improve what is most urgent?
\end{abstract}

Keywords: Public agenda; Hyperlocal journalism; Webjournalism; Tools.

\footnotetext{
${ }^{1}$ Docente na ESPM-SP; Pós-doutoranda na ECA-USP; e-mail: magalypprado@ gmail.com

${ }^{2}$ Mestre em Produção Jornalística e Mercado na ESPM-SP; e-mail: alexandre.adrian@gmail.com
} 


\section{Introdução}

A criação de uma plataforma digital de jornalismo em uma região rural, onde não existem veículos de comunicação locais relevantes e há uma limitação do acesso às redes telemáticas, pode ser um elemento transformador nas relações entre seus moradores, à medida em que venha à tona uma agenda pública - hoje indefinida ou mesmo não revelada -, que os leve a abrir caminhos para suas discussões.

O que verificamos em Gonçalves, cidade de 4.220 habitantes (IBGE, 2010), no sul de Minas Gerais (Brasil), é um morador pouco informado sobre sua realidade. O que de fato acontece - e a pesquisa realizada com moradores dá pistas - é a falta de uma agenda clara para a cidade, na compreensão da comunidade, que toma conhecimento das notícias apenas no bate papo, nos grupos de WhatsApp e nos avisos do alto-falante da igreja principal.

O engajamento digital é hoje, nos fluxos telemáticos em que vivemos, uma das principais razões para a sustentação de qualquer rede social, aplicativo ou plataforma digital, sejam estes de vendas, jornalísticos ou com qualquer outra finalidade. A convergência entre as redes sociais e as mídias móveis, que Lugano (2008) alerta se chamar "temporalidade always on", pela nova espécie de conexão que se formou, exige uma participação do usuário como nunca antes. Santaella (2010, p. 90), quando lembra as metáforas usadas para descrever os processos de acesso à informação diz que "desde a web 1.0 passamos da era da matrix, onde o foco da atenção se voltava para as máquinas e os códigos, para a era dos fluxos, onde o foco é a interação humana e seus laços sociais, culturais e afetivos".

É essa interação humana, da qual fala Santaella, um dos maiores desafios para o projeto de um site para a cidade como forma de conectar os moradores. O objetivo aqui é, por meio de reportagens, coleta de depoimentos, identificar os principais problemas da cidade, no intuito de retratar essa realidade e, de alguma forma, levar informações e conhecimento no sentido do encaminhamento destas questões.

"A internet é uma das invenções mais significativas do atual momento histórico, em que o verbo estar se conjuga no presente. É um lugar de encontro e de debate", diz Moraes \& Leal (2011, p.5, online). Os autores enfatizam que a realização da cidadania "tem a ver com a constituição de lugares de encontro e de comunicação para construir com o outro os sentidos da cidadania. [...] O futuro da cidadania e dos direitos humanos é a mediação, como cultura e como prática, para sua realização na experiência cotidiana das pessoas". 
Os temas prioritários - detectados a partir de visitas, sondagens e entrevistas - que podem mobilizar e conectar os moradores da cidade de Gonçalves, estão no centro dessa plataforma digital. O conteúdo inicial pretende retratar a vida dos moradores, desde problemas e necessidades até seus empreendimentos, no sentido de beneficiá-los e trazer as primeiras reivindicações mais urgentes. Para tanto, o site que começou a ser construído no final de 2017, com posterior colaboração da comunidade, abriu com as editorias ligadas à economia: sustentável, seja ambiental (de forma a não esgotar ou degradar recursos naturais), seja orgânica (agricultura e produção de alimentos sem agrotóxicos) e à economia criativa (manifestações culturais que reforcem a identidade e a troca de saberes) com a ideia de refletir sobre a realidade da região. Além destas, há um espaço dedicado a postagens dos próprios moradores, que são incentivados a produzir conteúdo e falar do próprio trabalho.

A plataforma que toma forma é intitulada "Gonçalves no Mapa" (goncalvesnomapa.com.br), na compreensão de que o mapa da cidade representa, antes de tudo, o reconhecimento do espaço, o pertencimento de quem vive ali. Todas as reportagens, as imagens, os vídeos e também posts dos moradores que participam com conteúdo (relatos, informações, denúncias, histórias) são georreferenciados no mapa no cabeçalho da home. A ideia é proporcionar, a partir do conteúdo, a conexão entre os temas e os habitantes, identificar locais, "amarrando os pontos" entre quem mora ali e quem frequenta a cidade, as atividades e as oportunidades detectadas.

Gonçalves, a $458 \mathrm{~km}$ de Belo Horizonte (capital do estado de Minas Gerais, na região sudeste do Brasil), é uma cidade rural (apenas um quinto de seus moradores vivem na região central, considerada urbana), tendo sua economia baseada em turismo e agricultura orgânica. É uma cidade pequena (em população) de grande extensão (187,596 $\mathrm{km}^{2}$ ), com uma densidade muito baixa, de apenas 22,5 hab. $/ \mathrm{km}^{2}$. Como comparação, Paraisópolis, cidade da qual Gonçalves se emancipou em 1963, tem uma densidade quase três vezes maior, de 58 hab./km2. Pouso Alegre, principal cidade da microrregião da qual Gonçalves faz parte, tem 265,88 hab./km². Isso, sem dúvida, tem grande impacto em como os moradores se distribuem na cidade, como se organizam nas suas atividades e como se deslocam, em um município onde as estradas são todas de terra e o transporte público se limita a ônibus escolares.

Um referencial teórico importante para esta discussão sobre espaço está no que Santos (2000, p. 02) defende como um papel ativo para a Geografia, definida como espaço geográfico, não como sinônimo de território, mas como território usado, "no intuito de construir, a um só tempo, uma teoria social e propostas de intervenção que sejam 
totalizadoras". Para o autor, o problema do espaço geográfico como ente dinamizador da sociedade é raramente levado em consideração:

Uma perspectiva de território usado conduz à ideia de espaço banal, o espaço de todos, todo o espaço. Trata-se do espaço de todos os homens, não importa suas diferenças, não importa sua força, o espaço de todas as empresas, não importa o seu poder. Este é o espaço de todas as dimensões do acontecer, de todas as determinações da totalidade social. (Idem, 2000, p. 2-3)

Para Santos, esta é a riqueza da geografia, na medida em que "podemos pensar, a um só tempo, os objetos (a materialidade) e as ações (a sociedade) e os mútuos condicionamentos entretecidos com o movimento da história". O mapa de Gonçalves, desta forma, quer pensar as relações estabelecidas entre o lugar, a formação socioespacial e o mundo.

Se estamos falando em territorialidade, do pertencimento do espaço, os conceitos de laços sociais no mundo digital aqui fazem todo o sentido. Está-se criando uma plataforma que, se tem o objetivo de conectar seus usuários, precisa mergulhá-los neste novo fluxo e dar a eles o sentido de pertencimento neste espaço. Não somente o site, mas todas as redes por onde serão espalhados estes conteúdos deverão criar novos laços. Santaella (2010, p. 93) lembra que na era das mídias sociais "a ênfase não é mais na informação que nós buscamos, mas sim na informação que recebemos através das nossas conexões sociais".

Por sua vez, João Canavilhas traz, na dimensão desse espaço aberto, as consequências, e atenta para uma das mais significativas, o vínculo, fazendo com que os cidadãos se sintam engajados, com opção consciente, a restaurar bens comuns:

las redes sociales facilitan un cambio en la forma como los usuarios se relacionan con los medios de comunicación, fortaleciendo los vínculos. Este enfoque mejora la transformación de las audiencias en las comunidades" e diz mais: o caráter de ser leal engrandece quando a "situación que tiende a generar lealtad de los consumidores por el desarrollo de sentimientos de pertenencia a una comunidade (CANAVILHAS, 2011, p. 133).

Quando falamos de uma cidade com pouco mais de quatro mil habitantes, com apenas uma rádio, de baixa audiência, e nenhum outro veículo local tradicional de comunicação, podemos considerar que estamos tratando de um nicho, um grupo pequeno com características próprias e interesses específicos. Ao falar em nichos, Santaella entende que mais fortes devem ser estes laços. Ela trata da questão quando afirma que na era dos fluxos - com a Web 2.0 e suas redes sociais - "virtual e real são sentidos como se 
fossem uma só e mesma coisa - uma mesma rede integrada através de dispositivos híbridos". O que vivemos hoje, Santaella já indica em 2010, "é um modelo aberto e livre da informação, na qual ela se espalha por todas as superfícies e ambientes". Rossiter (2006) entende que "a rápida transformação da cultura global dos fluxos indica uma reestruturação da arquitetura informacional da internet em função dos laços sociais". Os laços, nas redes sociais, só são possíveis porque o que os atores têm em comum, antes de tudo, é a própria comunicação, a vontade de se comunicar. Para Santaella,

(...) as redes, não vem ao caso se elas são científicas, organizacionais ou de relacionamento na internet, pois o que as constituem é o fato de que se formam e adquirem consistência à medida que alinham mais e mais atores. Assim, um ator-rede, que não é necessariamente um indivíduo, mas pode ser um coletivo, está sujeito a crescer e sua importância depende do número de atores que é capaz de atrair (idem, 2010, p. 51).

No âmbito da formação da consciência pública, Becker (2010, online) reforça que "as ações online ocorrem no sentido de tornar a internet uma fonte alternativa de informações, por meio de veículos de comunicação independentes, blogs, sites de organizações, listas de e-mails, fóruns de discussão e comunidades de relacionamento" (PRADO, 2015, p. 5).

\section{GONÇALVESNOMAPA}

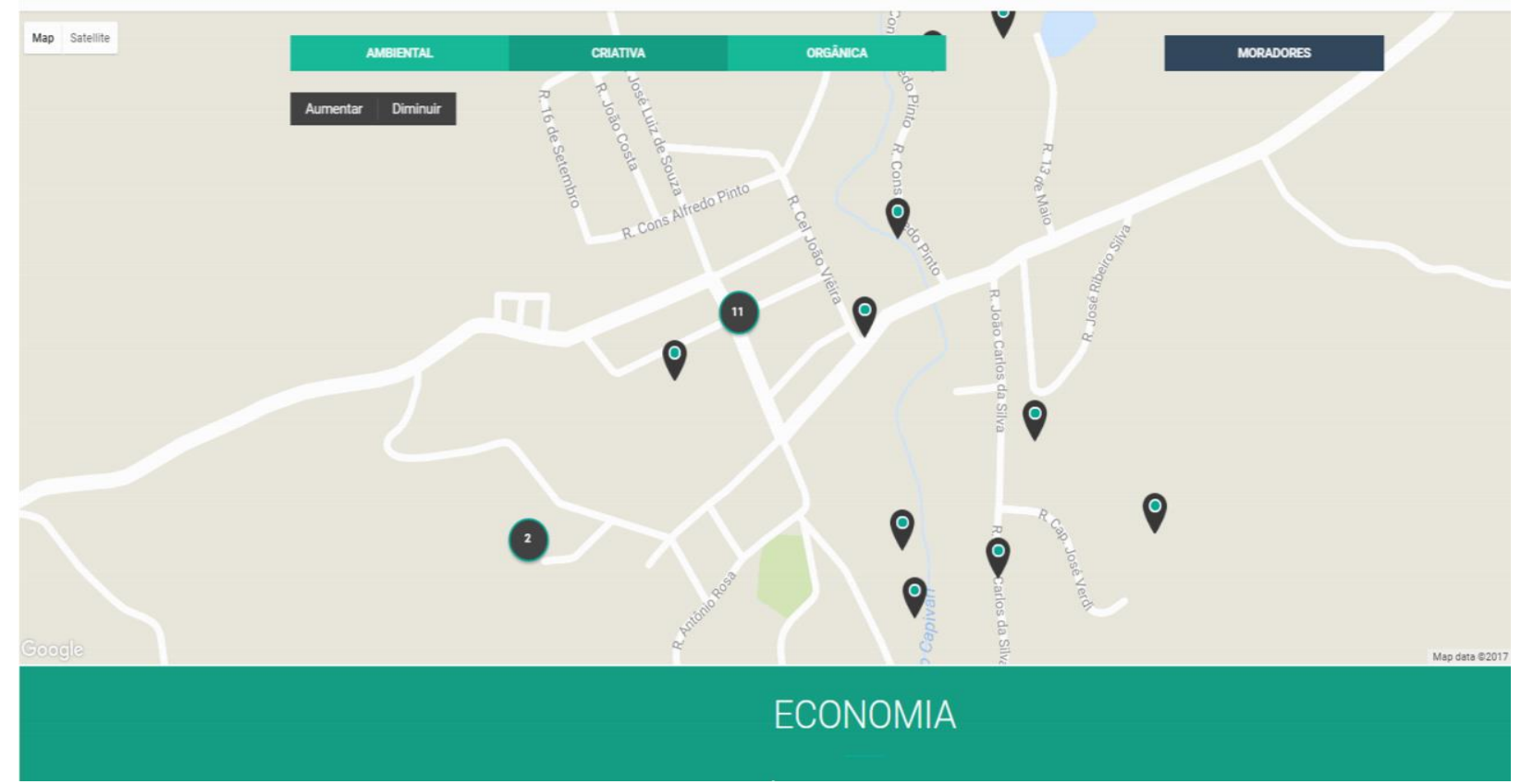

Figura 1. Cabeçalho da home que mostra o mapa com alguns dos pins das reportagens 
Ao participar e gerar conteúdo, o usuário comum começou com o surgimento das ferramentas amigáveis, ou seja, mais fáceis de publicação e distribuição, como a dos blogs. Essa participação ganhou força com a segunda fase, conhecida como web 2.0, cunhada pela empresa O'Reilly, em 2003. O precursor do termo, Tim O'Reilly, enfatiza que, nessa etapa, os aplicativos da www passam a utilizar os efeitos de rede e se tornam melhores, quanto mais são usados pelas pessoas, catalisando o potencial de emergência da inteligência coletiva (Prado, 2011).

Vejo o crescimento das tendências em direção à criação distribuída, conteúdos gerados por usuários, o compartilhamento em rede global e a categorização social. Do ponto de vista técnico, deve crescer o uso da computação em nuvem e das tecnologias de realidade ampliada. Jogos online multijogadores ficarão mais populares. Em resumo, a tendência básica é o aumento de poder da inteligência coletiva (LÉVY, 2006).

O objetivo deste estudo é propiciar um ambiente de acolhimento que incite debates sobre a agenda pública em uma cidade como Gonçalves, não acostumada a envolver grande parte de seus moradores para a discussão sobre a cidade, possibilitando então definir com mais clareza a linha editorial da plataforma compartilhada com eles para que comecem a participar mais amiúde. Para conhecer melhor o perfil dos cidadãos ${ }^{3}$, seus problemas e como se informam sobre o que acontece na cidade, foi realizada uma pesquisa durante dez dias do mês de maio de 2017, ouvindo de forma presencial e individual dez moradores considerados lideranças da região (a agente de saúde que visita mais de 200 famílias todos os meses, a organizadora da feira de orgânicos, que reúne dezenas de agricultores, a funcionária dos Correios há mais de 20 anos, entre outras). Este estudo busca entender, a partir de autores que dialogam com estes temas e da pesquisa, de que forma é possível engajar os moradores em torno desta nova ferramenta.

Portanto, mais do que descobrir onde e como os internautas-moradores consomem informação jornalística - para melhor considerá-los e atendê-los - a necessidade é alcançar os modos de relacionar a produção deste conteúdo daquele que vai, de fato, produzir (o profissional e o não profissional, o colaborador, o participante, ou seja, o humano, e acima de tudo [neste recorte] o cidadão ${ }^{4} \ldots$..). Investigar ainda como ele vai se

\footnotetext{
${ }^{3}$ Ser cidadão não tem a ver apenas com os direitos reconhecidos pelos aparelhos estatais para os que nasceram em um território, mas também com as práticas sociais e culturais que dão sentido de pertencimento, e fazem que se sintam diferentes os que possuem uma mesma língua, formas semelhantes de organização e de satisfação das necessidades. (CANCLINI, 2005, p. 35)

4 A prática do jornalismo cidadão ganhou maior relevância com a Web 2.0 (GILLMOR, 2005; BRAMBILLA, 2006; MALINI, 2008; PRADO, 2011; SHIRKY, 2011) e pode ser uma importante ação a ser desenvolvida em uma cidade pequena, rural, sem veículos de comunicação expressivos.
} 
apropriar das ferramentas do site e em quais ambientes digitais vai recircular e espalhar seu material, mesmo que de forma fragmentária, como constatamos muitas vezes (PRADO, 2016).

Como dito anteriormente, o único meio tradicional de comunicação na cidade se resume a uma rádio FM - Onda Verde (105.9), de baixa audiência ${ }^{5}$, confirmado pelos próprios entrevistados. Não há qualquer jornal ou periódico. A produção de notícias e sua divulgação a partir de plataformas de redes sociais digitais, como Facebook, vêm sendo utilizadas por alguns moradores (em sua maioria comerciantes com vínculo recente com a cidade) como forma de tratar questões de impacto para a comunidade, sem entretanto terem o envolvimento direto do poder público e, mais importante, sem uma compreensão clara dos próprios gonçalvenses e, portanto, sem um engajamento destes.

Exemplo disso é um movimento, organizado pelos moradores "de fora”, contra a construção de uma usina hidrelétrica na cidade, que ocorre desde 2015. As ferramentas utilizadas para mobilizar os cidadãos são, além da plataforma do Facebook, o aplicativo de mensagens WhatsApp com a gravação, em celulares, de depoimentos de moradores por alunos de uma escola da cidade. Eles rebatem os benefícios da construção (que produziria energia para a região a partir da usina construída em uma cachoeira da cidade) em inúmeros posts e outras formas de comunicação tradicionais - como faixas em pontos da cidade, abaixo-assinados, folhetos espalhados pelos bairros etc. Para eles, não nascidos ali, vindo de grandes cidades e envolvidos com algum tipo de negócio na região (comércio, plantação de produtos, criação de animais etc.), qualquer grande intervenção põe em risco a qualidade de vida existente hoje na cidade, o maior bem que os fez se instalarem ali.

Pode-se entender esse movimento como uma ação de mídia, à medida em que há uma mensagem sendo transmitida de forma planejada e ordenada por um grupo de cidadãos para o maior número possível de pessoas naquela comunidade? Haveria, assim, ainda que de forma precária, um agendamento? Lippmann (1922, p. 07) definia o termo Opinião Pública (com letras maiúsculas) 100 anos atrás, como “aquelas imagens que são feitas por grupos de pessoas, ou por indivíduos agindo em nome dos grupos", o que ilustra o movimento que ocorre em Gonçalves, quando um número de moradores busca dar

Ser cidadão não tem a ver apenas com os direitos reconhecidos pelos aparelhos estatais para os que nasceram em um território, mas também com as práticas sociais e culturais que dão sentido de pertencimento, e fazem que se sintam diferentes os que possuem uma mesma língua, formas semelhantes de organização e de satisfação das necessidades. (CANCLINI, 2005, p. 35)

${ }^{5} \mathrm{Em}$ abril de 2017 , de acordo com a radios.com.br, ficou em $554^{\circ}$ lugar em audiência entre 563 rádios no Estado de Minas Gerais, com 54 visitas. 
relevância a um tema de interesse dentro de uma comunidade. Na discussão que Lippmann faz sobre a objetividade jornalística "o mundo que temos que considerar está politicamente fora do nosso alcance, fora da nossa visão e compreensão". Ele é quem primeiro relaciona a agenda da mídia com a agenda pública, fundamentando a ideia de que não podemos ver tudo, tocar tudo, ouvir tudo.

O mundo tem que ser "explorado, relatado e imaginado", o que cabe ao jornalismo fazer, mas que estará impactado com o comportamento de cada um de nós, com o que interessa a cada um. "As imagens nas cabeças destes serem humanos, a imagem de si próprios, dos outros, de suas necessidades, propósitos e relacionamento são suas opiniões públicas".

A agenda pública, aquilo que é de interesse de um ator (mídia, governo ou da sociedade) em um processo de políticas públicas, vai ao encontro dos conceitos de Lippmann e irá convergir em agendas mais complexas, como a Agenda-setting (Wolf, 1994), Espiral do Silêncio ${ }^{6}$ (Noelle-Neumann, 1977) e Contra agendamento ${ }^{7}$ (Martins, 2007), nos quais o papel da mídia e sua influência sobre o cidadão são esmiuçados.

Para Noelle-Neumann, se alguns temas são agendados, outros são silenciados quando a mídia cria uma 'cultura' e age sobre ela. A autora identifica alguns fenômenos, como a ideia da consonância, que parte do princípio de que as semelhanças nos processos produtivos de informação são mais significativas do que as diferenças. De acordo com a autora, a opinião pública é a opinião prevalecente que faz com que os indivíduos consigam se expressar livremente, sem ameaças de isolamento ou exclusão pelos demais. "Em outras palavras, podemos descrever a opinião pública como a opinião predominante de que impõe uma postura e um comportamento submisso, enquanto isola e ameaça o indivíduo rebelde e, ao político, com uma perda de apoio popular" (NOELLENEUMANN, 1995).

Outros autores, como Silva (2007) e Barros Filho (1995) entendem que quanto maior o grau de relações interpessoais entre os membros de uma comunidade, menor a influência da mídia, isto é, o poder de agendamento. Estaria estabelecido então o contraagendamento. De acordo com Silva (idem), a partir dos anos 1990, as mídias digitais

\footnotetext{
${ }^{6}$ Se alguns temas são agendados, outros são silenciados quando a mídia cria uma 'cultura' e age sobre ela. Noelle-Neumann identifica alguns fenômenos, como a ideia da consonância, que parte do princípio de que as semelhanças nos processos produtivos de informação são mais significativas do que as diferenças.

7 A partir dos anos 1990, as mídias digitais abriram espaço para um novo protagonismo dos cidadãos, que são a base para uma agenda social mais autônoma, cuja determinação não está apenas nas mãos da mídia hegemônica.
} 
abriram espaço para um novo protagonismo dos cidadãos, que são a base para uma agenda social mais autônoma, cuja determinação não está apenas nas mãos da mídia hegemônica.

Uma das ideias que norteiam a agenda-setting, de acordo com Shaw (1977) é que

As pessoas têm a tendência para incluir ou excluir dos seus próprios conhecimentos aquilo que aos mass media incluem ou excluem do seu próprio conteúdo. Além disso, o público tende a atribuir àquilo que esse conteúdo inclui uma importância que reflete de perto a ênfase atribuída pelo mass media aos acontecimentos, aos problemas, às pessoas (Idem, 1977).

A partir daqui, usaremos o termo agenda pública como sinônimo de agendasetting, no entendimento de que os autores aqui citados (WOLF, 1994; TRAQUINA, 1995; HOHLFELDT, 1997) não fazem distinção entre estas denominações. Ainda que as outras correntes, como Espiral do Silêncio e Contra-Agendamento também possam ser consideradas nesta pesquisa, o conceito de agenda-setting encontra maior eco nas questões de Gonçalves que veremos a seguir.

Para Hohlfeldt (1997, p. 49), há condições para que essa agenda de fato se estabeleça, na compreensão de que “o fluxo da comunicação social é algo 'aberto', não um processo fechado como pressupunham as teorias de processos comunicacionais". Para ele, "as influências dos meios de comunicação sobre o receptor se dão a médio e longo prazo, não a curto prazo, como antes se acreditava" (Idem). Em tempos digitais, nos quais os meios são múltiplos e o receptor é também um emissor de informações, é pacífico de se concordar com o autor quando diz que "os meios não podem impor ao público 'o que pensar', mas certamente podem influenciá-lo sobre 'em que pensar'”.

É nesse contexto que a referência a García vem em boa hora:

Lo que podemos afirmar, de momento, después de estos años del tercer milenio, es que el periodismo local ha recuperado protagonismo en la sociedad digital. Y lo ha hecho no solo por el número de profesionales que diariamente lo practican, sino por la importancia que tiene la información de proximidad para los ciudadanos. Esta se ha convertido en vital para que hombres y mujeres puedan participar en la vida de la comunidad, es decir, para que dispongan de los datos útiles que hagan posible una verdadera integración como miembros de esa comunidad en las localidades donde desarrollan buena parte de su actividad (GARCÍA, 2008, p. 39).

Gandour (2016, p. 09) relembra o cenário no qual “a profusão de canais em mão dupla, potencializados pelas arenas permanentes de troca e interação que são as redes sociais, deu a qualquer indivíduo a possibilidade de editar, publicar e ter voz". No caso dos moradores de Gonçalves, existe a participação em potencial, após o engajamento 
provocado e incentivado pelo site dedicado a eles. Gandour alerta que é preciso avaliar impactos como a "mistura informativa" a qual estaríamos expostos, "composta por notícias geradas profissionalmente, muitas vezes fatiadas aos pedaços, e eventualmente misturadas com rumores, boatos e opiniões oriundas de várias fontes" (Idem).

O jornalismo cidadão, para diversos autores (GILLMOR, 2000; BRAMBILLA, 2006; PRADO, 2011), possui similaridades com o jornalismo participativo, colaborativo ou open source (aqui pelo conceito de se trabalhar com códigos abertos proporcionando melhorias). Ainda que haja diferenciações entre os termos, todos consideram que esta prática jornalística é realizada também pelo cidadão comum, atuante em alguma fase da produção da notícia - apuração, redação ou divulgação.

O jornalismo participativo na visão de Bowman e Willis (2003) é incorporado à democracia:

$\mathrm{O}$ ato de um cidadão ou de um grupo de cidadãos, em um papel ativo no processo de coleta, relatórios, análise e divulgação de notícias e informações. A intenção desta participação é fornecer informações independentes, confiáveis, precisas, abrangentes e relevantes que uma democracia requer. (BOWMAN E WILLIS, 2003)

Tal conceito é referendado por Gillmor (2008), para o qual o termo é entendido desta forma após combinação do "jornalismo cívico" e "jornalismo cidadão". A expressão "jornalismo cívico" (também chamado de "jornalismo público") foi criada no final dos anos 1980 e início da década de 1990, por Jay Rosen, Jan Schaffer e outros (GILLMOR, 2008). O autor relata que "havia a ideia de que as organizações de mídia ajudariam a definir agendas comunitárias de maneira mais explícita do que antes. Em certo sentido, o jornalismo cidadão de hoje é consequência disso".

A evolução tecnológica, sem dúvida, foi decisiva no processo. O que ficou conhecido como jornalismo cidadão "foi o resultado da democratização da era digital, do acesso à mídia e a ferramentas poderosas e baratas de criação de mídia. (...) Os blogs foram uma das primeiras e principais ferramentas", frisa Gillmor. A entrada do cidadão participando da mídia se instala e é lembrada por Prado (2011, p. 185), quando considera que, a partir daí, "o cidadão enxergou que poderia se inserir neste mundo".

Veículos que transformam o internauta em repórter surgem no mundo a partir da virada do novo século: Slashdot, Wikinews e, o mais emblemático, OhMyNews, site sul-coreano que tem como slogan "cada cidadão é um repórter", vêm na esteira da concepção de que é possível fazer jornalismo pelos olhos do próprio público, com ou sem mediação (idem, p. 176, 186). 
A questão de democratização da informação, do poder de qualquer cidadão, na rede, ser uma testemunha ocular deve ser analisada em diversos aspectos. Não se entrará aqui na discussão do uso desta ferramenta pelos grandes veículos - para Malini (2008), os veículos tradicionais veem a prática tanto como uma oportunidade (pelo diálogo "público") quanto como uma ameaça (perder uma “opinião pública” do veículo). A reflexão é o quanto as práticas exercidas pelo cidadão estão em consonância com o que se entende por jornalismo (KOVACH E ROSENSTIEL, 2004) e quais os interesses que estão em jogo. Se para Gillmor (2005, p. 55), “o crescimento do jornalismo participativo nos ajudará a ouvir", para Brambilla (2011) é preciso prestar atenção ao mau uso do espaço aberto e defende o diálogo.

Confiar que todos os internautas agem de modo coerente e benéfico em sistemas onde o anonimato é permitido, porém, seria ingenuidade. $\mathrm{O}$ perigo de mau uso da ferramenta aberta para destruir conteúdos úteis existe, mas este é um risco necessário se o jornalismo ambiciona um caráter dialógico. (BRAMBILLA, 2011)

Para a autora, este tipo de jornalismo "não surge com a intenção de desregulamentar nenhuma profissão, ao contrário: a meta é fortalecer as bases dialógicas de uma imprensa cuja função essencial é aperfeiçoar o potencial crítico do público".

É inegável que o jornalismo cidadão só faz crescer, no entendimento de que a democratização tecnológica no Brasil, fundamental para esta expansão, caminha a passos largos. Sob esta ótica democrática, Moretzsohn (2006) traz um contraponto ao taxar o que se pratica como um "mito libertário". De acordo com a pesquisadora, um dos alicerces do jornalismo está abalado, qual seja: “o caráter específico da mediação jornalística, que é o que legitima socialmente esse tipo de informação e impõe procedimentos necessários para que se lhe exija a indispensável credibilidade”. Para Moretzsohn, é grave a inversão de procedimentos para a publicação de alguma informação:

Em vez de primeiro filtrar para depois publicar, o jornalismo participativo trabalha com a lógica inversa, publicando primeiro e filtrando depois. Porque isso faria parte da própria lógica de autocorreção propiciada pela troca de informações entre esses cidadãos ativos (idem, p. 68).

Moretzsohn, ao trazer Deuze (apud Bowman e Willis, 2003, p. 35), para quem o jornalismo cidadão é "mais viável se aplicado em nichos de mercado especializados", indica a direção do que se pretende com a pesquisa/ação em Gonçalves, pondo em prática o jornalismo produzido pelos próprios moradores de forma integrada a outras ações, em 
uma região que ainda tem limitações digitais. O exercício do fazer jornalismo específico deste projeto está condicionado ao modelo de ferramentas digitais que são ali utilizadas e que, ainda estão sendo levantadas para passar por análises no intuito de verificar as aplicabilidades na região, com o propósito de torná-la uma cidade inteligente.

Os chamados "jornalistas-cidadãos", que contribuem com a coleta de dados e a transmissão e disponibilização de testemunhos e relatos em tempo real, estão a todo vigor em modo crescente e o ideal é tê-los em parceria, mesmo que com isso o gerenciamento da tarefa já costumeira de checagem de informações tenha de ser redobrado, sem contar o esforço para manter a qualidade do texto, os valores profissionais éticos e o compromisso com o interesse público (PRADO, 2011).

Aroso (2003) alerta para o lado perigoso ao lidarmos com as colaborações. “Também é visto como sendo negativo o facto de se utilizarem materiais produzidos por cidadãos, porque a estes não se pagam, mas o trabalho de produção de notícias não vive só de vontade, é preciso dinheiro, tempo e dedicação" e acrescenta que também se questiona a qualidade da informação, "pois os cidadãos não têm formação sólida em métodos e valores jornalísticos, surgindo 'notícias' sem interesse, não verdadeiras, inexatas e até mesmo ofensivas". A autora lembra outro detalhe valiosíssimo: "a credibilidade informativa também está em causa: sem qualquer controle da informação, é difícil saber o que é verdadeiramente notícia e não mera opinião ou especulação".

(...) neste cenário participativo, o papel do jornalista será: avaliar, editar e publicar o material produzido pelos cidadãos, à semelhança do que faz com qualquer outra fonte de informação; organizar comunidades, criando relações e mobilizando as pessoas reunidas por interesses e necessidades comuns; fazer a diferença, reforçando os princípios éticos e deontológicos de verificação a informação, na busca da verdade, com independência e objetividade, procurando promover um espaço público de debate. Isto vai ao encontro da ideia que "o jornalismo on-line influencia os vários aspetos da realidade jornalística. Um desses elementos, ou mesmo o principal, é o jornalista que, também ele, é profundamente afetado (...). Perante uma nova realidade profissional, então, as competências que são exigidas ao jornalista, como é natural, também mudam (AROSO, 2003).

Essa situação crucial (sobre os colaboradores) em questão perpassa nosso estudo não somente por consequência do estado da arte do jornalismo digital apontar a presença do jornalismo colaborativo desde o nascimento da web 2.0 e dos próprios princípios da web - resumidamente: livre e aberta -, bem como pela necessidade intrínseca de tais figuras trabalharem lado a lado (frisando a devida supervisão dos profissionais), 
caracterizando, assim, um dos pilares dessa chamada nova era da comunicação, a digital (PRADO, 2011).

\section{Lado a lado com os profissionais da tecnologia}

Autores com pesquisas cujo corpus aproximam-se deste estudo refletem problemáticas similares. $\mathrm{O}$ fato de sabermos pouco sobre como "os tecnólogos cívicos e os jornalistas de dados se relacionam com o trabalho uns dos outros, como eles se complementam e em que eles diferem", foi o mote de Stefan Baack em artigo da Digital Journalism (2017, online), apesar do fato de que é reconhecido que o processo de elaboração de notícias é "cada vez mais moldado por forças em rede que abrangem múltiplas identidades profissionais, ideologias de informação e suposições sobre como as notícias e a vida pública se cruzam" (ANANNY \& CRAWFORD, 2015 apud BAACK, 2017). Os pesquisadores complementam: “Tal vinculação é relevante, não só porque existe uma cooperação direta e sobreposição entre eles, mas porque essa relação está configurando-se como o jornalismo e as formas de envolvimento cívico estão respondendo à divulgação progressiva da vida social” (VAN DIJCK, 2014 apud BAACK, 2017). Baack apresenta conclusões de um estudo de caso qualitativo que "explorou como os jornalistas de dados e os tecnólogos cívicos entendem as próprias práticas e como eles trocam, recuperam, modificam, rejeitam e se relacionam”.

Podemos traçar paralelos quando tentamos (como jornalistas munidos de dados de Gonçalves e de seus moradores) nos aproximar para montar um ambiente tecnológico com finalidade cidadã.

Nas notícias divulgadas por este grupo de moradores de Gonçalves, a preservação da natureza está acima da usina hidrelétrica, mesmo que os impactos não sejam tão grandes, como afirma a empresa. O grupo invoca a necessidade da preservação, da manutenção das riquezas naturais a qualquer custo. Eles entendem que a população mais simples não tem a exata noção de preservação e que, portanto, estas mensagens se fazem necessárias.

O que pensam os moradores sobre temas como este - a construção de uma usina hidrelétrica - estão na agenda da cidade e de seus cidadãos. Foi realizada uma pesquisa de campo entrevistando moradores de Gonçalves, com diferentes perfis etários, econômicos e profissionais. A condição era que tivessem nascido ou morassem na cidade há muito tempo e que, por conta de suas atividades, tivessem um contato diário com muitas pessoas. O termo liderança, aqui, pode ser entendido, efetivamente, como um influenciador. Foram levantados 19 perfis e, destes, dez responderam às duas questões. 
Abaixo, quem foi entrevistado, e sua profissão e o porquê de ele ser uma liderança na região:

Quadro 1: Os cidadãos influentes de Gonçalves

\begin{tabular}{|l|l|}
\hline \multicolumn{1}{|c|}{ Cidadão } & \multicolumn{1}{|c|}{ Profissão } \\
\hline Sebastião de Souza - Thiana & $\begin{array}{l}\text { Agricultor, mantém uma grande horta orgânica que abastece } \\
\text { vários estabelecimentos. }\end{array}$ \\
\hline Maura Oliveira de Paula & $\begin{array}{l}\text { Comerciante e marceneira, tem loja de móveis. Em um guia de 20 } \\
\text { lojas do centro, é a única proprietária que nasceu e cresceu na } \\
\text { cidade. }\end{array}$ \\
\hline Ivana Vieira & Trabalha há 22 anos nos Correios. \\
\hline Júlio César Ribeiro & Auxiliar administrativo e vereador. \\
\hline José Luiz Benedito Morais - Zil & Trabalha na lavoura, jardineiro e vereador. \\
\hline $\begin{array}{l}\text { Benedito Rafael Barbosa } \\
\text { Expedito Sorriso }\end{array}$ & Trabalha em uma rede de supermercados, e percorre a cidade. \\
\hline Elza Raimundo de Souza Alves & Comerciante, dona da quitanda mais popular da cidade. \\
\hline Cida Castro & Agente de saúde, atende 206 famílias todos os meses. \\
\hline Maristela Canepelle & $\begin{array}{l}\text { Coordenadora da Feira Orgânica, trabalha com 60 pessoas, sendo } \\
32 \text { produtores orgânicos (única não gonçalvense, vive na cidade } \\
\text { há 15 anos) }\end{array}$ \\
\hline Benedito Rafael Barbosa & Pedreiro, serralheiro e socorrista. \\
\hline
\end{tabular}

Todos responderam às perguntas iniciais para compreendermos o que faziam, como tinham contato com um número considerável de outros moradores, se tinham crescido na cidade e se tinham identificação com a região em que moram ou moraram. A escolha de dois vereadores deu-se não por esta condição, mas pelo fato de serem lideranças reconhecidas em seus bairros (indicados por outros moradores). Ainda que no universo de entrevistados não haja uma distribuição uniforme no que diz respeito ao espaço geográfico, cinco deles são oriundos de bairros fora da região central e suas demandas estão refletidas na pesquisa.

Foram duas as perguntas relativas àquilo que pode ajudar a entender qual a agenda pública da região: 1. Como você se informa sobre o que acontece em Gonçalves? 2. O 
que você entende como sendo os principais problemas que os moradores vivem? Quando não havia a compreensão clara do entrevistado sobre o que se buscava, era perguntado: O que falta na cidade para os moradores?

A seguir, as palavras-chaves das respostas, sem identificar as pessoas:

\section{Quadro 2: Palavras-chave com as respostas dos cidadãos sobre os problemas da cidade.}

\begin{tabular}{|c|c|c|}
\hline & $\begin{array}{l}\text { Como você se informa sobre o que } \\
\text { acontece em Gonçalves? }\end{array}$ & $\begin{array}{l}\text { O que você entende como sendo os } \\
\text { principais problemas que os moradores } \\
\text { vivem? }\end{array}$ \\
\hline Cidadão 1 & $\begin{array}{l}\text { No bar/conversas/na feira } \\
\text { dos } \\
\text { orgânicos/alto-falante }\end{array}$ & $\begin{array}{l}\text { Falta de recursos para a saúde/educação } \\
\text { fraca em relação a anos anteriores }\end{array}$ \\
\hline Cidadão 2 & $\begin{array}{l}\text { A gente não sabe das coisas na } \\
\text { cidade/WhatsApp/através dos } \\
\text { alunos/radio não funciona bem/igreja }\end{array}$ & $\begin{array}{l}\text { Mais opções culturais e esporte/falta o que } \\
\text { a criança e adolescente fazer, } \\
\text { principalmente na zona rural }\end{array}$ \\
\hline Cidadão 3 & $\begin{array}{l}\text { Boca a boca/alto-falante da igreja } \\
\text { matriz/van dos estudantes/igrejas }\end{array}$ & $\begin{array}{l}\text { Diversão/cinema/tudo é voltado para os } \\
\text { turistas/ não tem pronto socorro }\end{array}$ \\
\hline Cidadão 4 & $\begin{array}{l}\text { Prefeitura/Facebook/boca a } \\
\text { boca/cartazes/panfletos nos bairros }\end{array}$ & $\begin{array}{l}\text { Má conservação estradas de terra - bueiro, } \\
\text { calçamento/falta ônibus circular - pedido } \\
\text { dos moradores }\end{array}$ \\
\hline Cidadão 5 & Boca a boca & Moradores pedem uma van circular \\
\hline Cidadão 6 & $\begin{array}{l}\text { Boca a boca / saúde vai de casa em } \\
\text { casa }\end{array}$ & $\begin{array}{l}\text { Falta de área de lazer/ter um clube/ } \\
\text { condições da estrada/locomoção }\end{array}$ \\
\hline Cidadão 7 & Boca a boca & Lazer/não tem clube, cinema \\
\hline Cidadão 8 & WhatsApp & Manutenção das estradas \\
\hline Cidadão 9 & $\begin{array}{l}\text { WhatsApp/Facebook/alto-falante } \\
\text { da igreja matriz }\end{array}$ & $\begin{array}{l}\text { Falta de plano diretor/plano de } \\
\text { desenvolvimento sustentável/mais } \\
\text { cultura/projetos de geração de renda }\end{array}$ \\
\hline Cidadão 10 & $\begin{array}{l}\text { WhatsApp/rádio, mas toca mais } \\
\text { música que dá aviso }\end{array}$ & $\begin{array}{l}\text { Falta lazer/ficar pronto centro } \\
\text { poliesportivo/demora em marcação de } \\
\text { exames de saúde/educação fraca em } \\
\text { relação anos atrás }\end{array}$ \\
\hline
\end{tabular}


Embora já se constatado, as respostas à primeira pergunta deixam claro que não há um veículo de comunicação relevante na cidade. Pelos menos dois dos cidadãos, durante a entrevista, falam que a rádio Onda Verde é pouquíssimo ouvida na região central e também tem pouca relevância nos bairros. Como cidade pequena que é, o "boca a boca", juntamente com o alto-falante da igreja matriz, no centro, são as formas mais comuns de os habitantes de Gonçalves saberem o que acontece ali. A igreja, neste caso, dá avisos de utilidade pública (vacinação, por exemplo), assim como horário de missas. Outros entrevistados dizem usar as redes digitais (WhatsApp e Facebook, basicamente) para a formação de grupos e, assim, troca de informações. Ainda assim, as páginas de Facebook existentes hoje ${ }^{8}$ se resumem à promoção de atrativos turísticos, não como um meio de divulgar notícias sobre a cidade.

Quanto à segunda questão, entre os problemas que estes moradores vêm na cidade aparece, em primeiro lugar, a falta de lazer. Isso fica evidente nas respostas de falta de cinema, de teatro, de uso do clube da cidade, das poucas atividades esportivas. Depois, problemas ligados à qualidade da educação e manutenção das estradas. Chama a atenção as respostas dos dois vereadores. Ambos foram evasivos, de início, não citando grandes problemas.

Quando incitados a dizer o que ouviam dos moradores durante as campanhas eleitorais, os dois relataram que a principal demanda é que houvesse transporte público (ônibus/van) que circulasse por toda a cidade, já que hoje a Prefeitura disponibiliza transporte apenas para estudantes. A constatação de que falta lazer (a maioria fala de atividades para crianças e jovens) mostra como uma cidade turística, que dispõe de uma infraestrutura razoável de pousadas, restaurantes, lojas e realiza diversos eventos ao longo do ano, pouco atende ao seu morador. Ainda que todas estas atividades gerem empregos, eles não suprem necessidades de quem vive ali, como em questões ligadas a serviços e às necessidades naturais de uma cidade (mobilidade, saúde, educação, lazer). Por outro lado, a questão da usina sequer é citada pelos entrevistados. Temas que podem ter grande impacto na cidade, de interesse público, ligados à sustentabilidade, seja ambiental ou econômica, um plano diretor (atualmente em discussão na Câmara dos Vereadores), por exemplo, passam ao largo das respostas destas pessoas, que, como lideranças, podem ser influenciadoras na cidade. É correto afirmar que as principais demandas, aqui de interesse

\footnotetext{
${ }^{8}$ Em uma raspagem de dados realizada em perfis do Facebook, em 24 de maio de 2017, aparecem quatro páginas, três delas direcionadas ao turismo (Gonçalves, Gonçalves MG, Carnaval em Gonçalves) e uma do grupo intitulada Em Defesa de Gonçalves.
} 
do público, estão relacionadas a questões mais imediatas (falta de lazer, problemas na estrada, ausência de transporte etc.), mas mostram que nem uma eleição recente para a Prefeitura (em outubro de 2016) os fez refletir sobre uma agenda da mídia ou política (no entendimento que informações sobre os candidatos e suas agendas foram veiculadas à época). Temas de impacto maior, desta forma, não são considerados.

Pela amostra que a pesquisa oferece, não se pode dizer, com certeza, que existe uma agenda pública comum em Gonçalves, no sentido de que não há temas da comunidade que estejam conectados com os movimentos da cidade, sejam eles públicos ou privados. Este descompasso é uma oportunidade, portanto, de buscar conectar os moradores em torno de uma agenda efetiva, que seja construída e liderada por eles. Estamos falando, então, de viabilizar a prática do jornalismo hiperlocal.

Como uma das marcas da internet é a quebra de fronteiras físicas, uma edição de jornal pode virar global e pode ser acessada por todos, se houver interesse, seja ela nacional, ou mesmo a local, que ganha a versão hiperlocal - protótipo que engloba este raciocínio inicial, pois revela o localismo das informações do espaço físico somadas às do ciberespaço, que só fazem sentido se apuradas e produzidas com a participação dos moradores e frequentadores. O conteúdo hiperlocal na web e fora dela se dá pela cobertura de uma região geográfica específica, tendo os jornalistas a efetiva colaboração dos moradores e/ou frequentadores (PRADO, 2017).

Um exemplo de aplicação é o jornal Extra que "mantém dois jornais hiperlocais impressos, o Mais Baixada (circulação de segunda à sexta) e o Mais São Gonçalo (abrange também Niterói e Itaboraí, e circula de segunda à sábado). Nas duas publicações, há um espaço fixo na página 2 com conteúdo basicamente sugerido pelo leitor via WhatsApp. Os hiperlocais também têm a sua própria conta de WhatsApp - o número é divulgado nas edições impressas e nas páginas dos hiperlocais no Facebook" (PRADO, 2017, p. 228). 


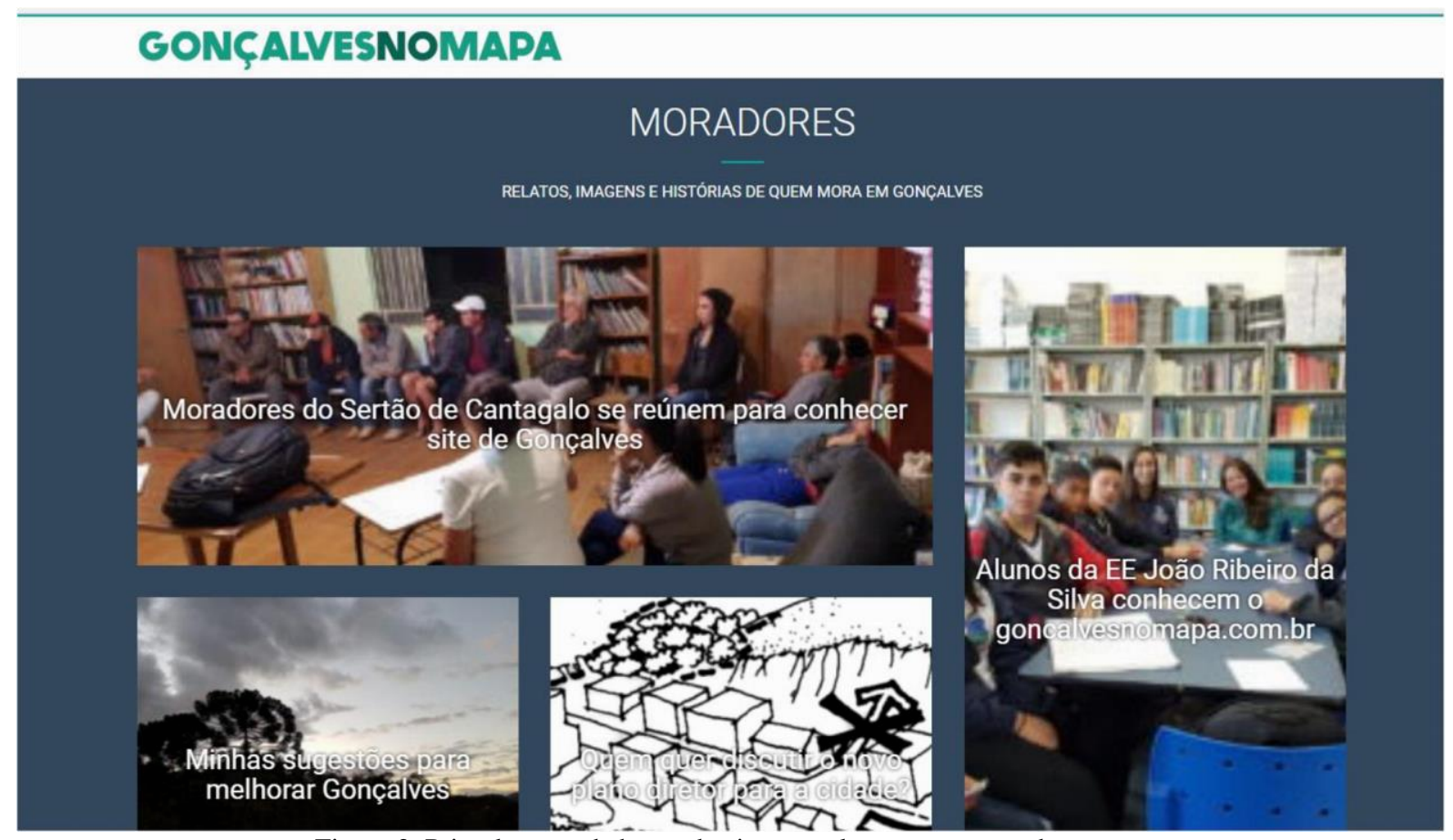

Figura 2. Print de parte da home do site goncalvesnomapa.com.br

A plataforma que está sendo desenvolvida em Gonçalves tem como objetivo primordial conectar os moradores, oferecendo a eles diferentes assuntos (por meio de notícias, entrevistas, vídeos, imagens) fortemente calcados nas principais demandas da comunidade. Só será possível obter o engajamento de uma maioria se de fato este material retratar a realidade local e se for possível, por meio desta produção jornalística, indicar caminhos para a transformação e solução de problemas, incitando o público-internautacidadão a contribuir com relatos dos fatos ao seu redor e, assim, aumentar a informação. Se atingir seus objetivos, esta ferramenta deverá dar visibilidade a uma agenda pública, aos temas que agora estão sendo revelados pelos moradores.

Baack, em estudo citado anteriormente, concentrou-se no Correctiv - uma redação de pesquisa semelhante à ProPublica (EUA) - especializando-se em investigações que são compartilhadas com outros meios de comunicação. A ideia é treinar com os métodos de investigação em uma incorporação de práticas e aplicações inspiradas pela tecnologia cívica e ajudar os cidadãos a acessar a informação a que têm legalmente direito. A proposta é ajudá-los a tornar a sociedade mais transparente e, assim, promover o engajamento democrático coletando dados para esclarecer fenômenos que não possuem transparência, e depois publicar o banco de dados com ferramentas para investigar isso junto às histórias (CORRECTIV, 2016). 
Esta ferramenta de pesquisa destina-se a ajudar os meios de comunicação locais a fazer as próprias investigações locais, mas também incorpora claramente a ênfase da tecnologia cívica em também tornar mais fácil aos cidadãos permitindo que explorem o problema relatado, personalizem histórias de investigação, verifiquem sua situação local e assim, saibam como ele os afeta pessoalmente.

Desde o surgimento da internet, os veículos de comunicação vêm passando por uma transformação radical, e quando se olha a produção de notícias locais, o cenário é desafiador. Nos Estados Unidos, o enxugamento de redações de veículos tradicionais levou a uma diminuição significativa de profissionais em cidades menores e até mesmo ao fechamento de jornais nestas localidades (Sorj, 2011), algo que já ocorre no Brasil (Gandour, 2016). Ao mesmo tempo, houve uma proliferação de sites com produção de notícias locais, de interesse da comunidade, favorecidos pela facilidade de se criar veículos digitais e, assim, ocupar este novo espaço. É o que corrobora Xosé Lopez García:

La dimensión local, que es un factor básico y permanente del periodismo, cobra ahora nuevos impulsos en todos los medios que actúan en los escenarios locales. En la complejidad de ese espacio de comunicación existen iniciativas que buscan prácticas profesionales muy implicadas en la vida local, así como la participación de los usuarios en los procesos de producción de la información (GARCÍA, 2008, p. 24).

De acordo com Waldman (2011), em uma análise sobre a realidade destes novos sites nos Estados Unidos,

Organizações de notícias sem fins lucrativos surgiram para preencher lacunas em vários setores, incluindo saúde (Kaiser Health News), escolas (Public School Notebook, The Hechinger Report, Education News Colorado) e cobertura externa (Pulitzer Center on Crisis Reporting e o International Reporting Project), entre outros. A Fundação John Locke, um think tank libertário/ conservador na Carolina do Norte, publica o Carolina Journal sobre políticas estaduais e locais (Idem, 2011 p. 188).

Sorj, por sua vez, lembra que enquanto a massa de informação gerada hoje pela internet está

enormemente fragmentada e em geral os sites se concentram em textos de opinião e comentários, baseados em material produzido originalmente pela imprensa profissional, a informação pública inédita na internet se dá fundamentalmente ao nível microlocal. (SORJ, 2011)

O que para o autor é algo limitador, já que esta informação pública teria dificuldades, pelo contexto atual, de se ampliar em um meio de múltiplas plataformas, no caso de Gonçalves pode ser um facilitador, pela conjuntura já exposta aqui. A partir do engajamento e visibilidade que pode-se obter com a nova plataforma, a produção e 
distribuição das notícias têm condições de descortinar estas demandas, de uma forma que antes, com a mídia tradicional, talvez não obtivesse o mesmo êxito.

Machado (2003, p. 18) deduz que a multiplicação dos difusores altera as relações entre os jornalistas e as fontes porque "transforma os usuários do sistema em fontes. $\mathrm{O}$ fator diferencial do jornalismo digital consiste na redistribuição dos poderes de controle entre todos os membros do sistema, considerando que os usuários são ao mesmo tempo fontes e produtores de conteúdos".

É importante buscar, em Lima Júnior (2016), o registro de que o conceito do jornalismo hiperlocal foi "estruturado de acordo com o desenvolvimento histórico do jornalismo comunitário oriundo da mídia impressa". Mas hoje, pelo fornecimento de notícias e serviços locais em um ambiente digital, ganha outra dimensão. Radcliffe (2012) determina que o jornalismo hiperlocal refere-se à uma localidade "pequena" e "fornece notícias ou serviços de conteúdo on-line pertencentes a uma cidade, vila, único código postal ou outra comunidade pequena, geograficamente definida." É, portanto, o jornalismo que antes era apenas local agora inserido em sistemas informativos, como sites e blogs, de forma ubíqua.

O jornalismo hiperlocal, assim, tem funcionado por intermédio da contribuição de pessoas físicas ou jornalistas, permitindo

[...] acessibilidade aos membros da comunidade, ativistas, estudantes, jovens e ao público em geral. Para se engajarem na mídia localmente e globalmente é necessário compartilhar problemas, pontos fortes, preocupações e as necessidades da comunidade; estratégias, organizar e fazer chamada para a ação; compartilhar pesquisas e resultados da comunidade envolvida em eventos de forma participativa; proporcionar a consciência geral sobre o trabalho da comunidade, vitórias e eventos. Este tipo de ferramenta de comunicação se expande conforme você compartilha e usa a pesquisa para fazer questões e estratégias, abrindo as portas para a comunidade local no compartilhamento de informações (BURNS; BONILLA, 2012, p. 5).

Santaella (2008) defende que, com a convergência das novas redes móveis de telecomunicações, estão surgindo novas estruturas espaciais interativas e novas práticas culturais:

Trata-se de serviços baseados em locais que, por meio da rede geoespacial, estão ligando os bits imateriais da mídia e informação com lugares físicos do espaço público urbano. São práticas tecno-sociais com o potencial de gerar formas de participação pública que reconectam as dimensões materiais do espaço físico com os recursos participativos da esfera pública virtual (SANTAELLA, 2008, p. 130). 
Ross Hawkes, fundador do site de notícias hiperlocais, Lichfield Live, na Inglaterra, em uma reportagem do The Guardian (2014, online), resume bem a questão deste tipo de jornalismo hoje: "Se você não presta atenção com o que ocorre ali e o que as pessoas estão dizendo, como você pode representar com precisão as opiniões da comunidade? Parte do crescimento e do sucesso percebido do novo movimento hiperlocal é a paixão e o conhecimento para as comunidades que nós servimos."

Santaella (2008, p. 130) levanta a questão do retorno, ainda que transformado, da interação humana cara a cara: “Com as redes de comunicação móveis baseadas em localizações ressurgem os pontos de encontro no espaço físico de um ambiente urbano", diz, e ressalta que "o parâmetro da localização geográfica é reintroduzido", mas reforça que "em atividades que continuam sendo mediadas por computador". O espaço virtual em que a comunicação ocorre, completa Santaella, "é mapeado para o espaço físico habitado pelos corpos materiais dos participantes. Assim, o contexto espacial virtual é mapeado no mundo físico e o contexto espacial híbrido resultante torna-se a arena do processo interativo".

Neste cenário, as ferramentas de geolocalização são fundamentais para garantir a prática hiperlocal. A aplicação de novas tecnologias encontra-se cada vez mais em um jornalismo que considere os dispositivos móveis como a plataforma mais adequada. Para Lima Júnior (2016), as formas de produção e distribuição de conteúdo se dão com o uso de Application Programming Interface (API). De acordo com a descrição do autor, a API é uma tecnologia interoperável, que pode ser modelada para facilitar o intercâmbio de dados estruturados, possibilitando a entrega de conteúdos sob medida e adaptados. Estas APIs podem ser desenvolvidas "para públicos específicos com configurações locais fornecendo informações e serviços jornalísticos em qualquer lugar (espaço físico) e a qualquer hora por intermédio de um dispositivo de comunicação móvel” (2016, p. 122). Essas e outras condições são as que possibilitam oferecer informação local para o morador (de Gonçalves) através de dispositivos móveis, favorecendo a criação de ambiente hiperlocal dando ênfase à sustentabilidade e enaltecendo a cultura da região.

\section{Considerações}

A capacidade de engajamento desta nova plataforma será determinante para que este espaço digital funcione, de fato, como um catalizador dos anseios de seus usuários, no caso, do maior número possível de moradores e visitantes frequentes de Gonçalves. Desta forma, eles se sentirão partícipes do processo, produtores e beneficiários de todo o fluxo informacional que ali se estabelecer. 
A prática do jornalismo hiperlocal se dá hoje pela possibilidade de, a partir de um fato regional, fora dos grandes centros, ganhar um alcance sem limites nas redes digitais. Isso tem maior relevância se o produtor da notícia for também um nativo, aquele que puder ter o olhar da sua aldeia e esta notícia fizer sentido como ressonância para a região e também para além dela. Se isso ocorrer, o engajamento de fato acontece e permite o envolvimento de mais e mais usuários.

Vale voltar a Santos e seu território usado para refletir que estamos falando de terra e de pessoas, de pertencimento, de quem tem mais ou tem menos poder. Para o autor, é dessa combinação que temos “o arranjo singular dos lugares”. É preciso entender o papel do que ele chama de "atores hegemonizados" e de sua luta para garantir a própria sobrevivência nos lugares. De acordo com Santos,

somente assim responderemos à questão crucial de saber como e o porquê se dão as relações entre a sociedade como ator e o território como agido e, ao contrário, entre o território como ator e a sociedade como objeto de ação. É essa, ao nosso ver, a maneira de encontrar um enfoque totalizador, que autorize uma intervenção interessante para maior parte da população (idem, 2000, p. 13).

A pesquisa realizada com moradores de Gonçalves traz dados de como eles se informam, o que consomem de notícias locais e como enxergam demandas para a comunidade; assim, dá um primeiro passo para desvendar a agenda pública da cidade. São resultados que levam à outras questões, como a necessidade de se aprofundar e tentar chegar mais perto dos reais problemas dessas pessoas. Há um caminho jornalístico que não pode se confundir com os interesses da gestão pública, daquilo que não é função da ferramenta e de toda a mobilização que se busca com este trabalho.

É fundamental trazer de um lado o hiperlocalismo com notícias pertinentes à Gonçalves, que possam ser relevantes na era do fluxo, e de outro os instrumentos de melhoria da qualidade de vida, com ações, associações, inventos e criações de suportes digitais como aplicativos, outros sites da redondeza, redes de ajuda, cooperações, trocas e serviços para os habitantes.

Finalizamos citando Boltanski e Chiapello em cidade por projetos, quando o projeto é a ocasião e o pretexto para a conexão, mesmo que reunindo temporariamente um grupo de pessoas bem diferentes e "apresentando-se como um extremo de rede, fortemente constituída durante um curto período de tempo, mas que permite forjar vínculos mais duradouros, mesmo que permaneçam desativados por algum tempo, estarão sempre disponíveis" (BOLTANSKI e CHIAPELLO, 1999-2009, p.155). 
Tais ações, combinadas e exitosas nos seus propósitos, poderão de fato gerar benefícios concretos para aquela comunidade e, assim, proporcionando produzir ciência quando se olha a realidade e tenta-se dar retorno a sociedade.

\section{Referências}

AROSO, Inês (2003). A Internet e o Novo Papel do Jornalista, in Biblioteca Online de Ciências da Comunicação (BOCC). Disponível em: <http://bocc.ubi.pt/pag/arosoinesinternetjornalista.pdf $>$. Acesso em: 22 abr. 2015.

BAACK, Stefan. Practically Engaged. The entanglements between data journalism and civic tech. Published online: 13 out. 2017. Disponível em: <http://www.tandfonline.com/doi/full/10.1080/21670811.2017.1375382>. Acesso em: 27 out. 2017.

BARROS FILHO, C. Ética na comunicação. 5ed., São Paulo: Summus, 2003.

BOLtANSKI, Luc; CHIAPELlO, Eve. O Novo Espírito do Capitalismo. São Paulo: Martins Fontes, 2009.

BOWMAN, S.; WILLIS, C. We Media.How audiences are shaping the future of news and information, Stanford: The Media Center at The American Press Institute, 2003. Disponível em:www.hypergene.net/wemedia. Acesso em: 20 nov. 2016

BRAMBILlA, Ana Maria. Jornalismo Colaborativo (e microjornalismo), 2011. Disponível em: <http://paraentender.com/internet/jornalismo-colaborativo>. Acesso em: 28 nov. 2016.

BRAMBILLA, Ana Maria. Jornalismo open source: discussão e experimentação do OhMyNews

International. Dissertação (Mestrado em Comunicação e Informação) - Faculdade de Biblioteconomia e Comunicação, Universidade Federal do Rio Grande do Sul, Porto Alegre, 2006. Disponível em: <http://www.lume.ufrgs.br/bitstream/handle/10183/8457/000576267.pdf>. Acesso em: 22 nov. 2016.

BURNS, Janice. C.; BONILLA, Taicha. Hyperlocal communication. 2012. Disponível em:http://v5.healthycity.org/sites/hc.v5.live/files/amazon_s3/article_file/Hyperlocal\%20 Commu nications.pdf. Acesso em: 4 jun. 2017.

CANAVILHAS, João (2011). Del gatekeeping al gatewatching: el papel de las redes sociales en el nuevo ecosistema mediático. In Periodismo Digital: convergencia, redes y móviles. Fernando Irigaray, Dardo Ceballos e Matía Manna (orgs.).

CANCLINI, Néstor García. Diferentes, desiguais e desconectados. Rio de Janeiro: UFRJ, 2005.

CORRECTIV. 2016. Frequently Asked Questions. CORRECTIV Homepage. Disponível em: <https://correctiv.org/en/correctiv/faq/>. Acesso em: 26 out. 2017.

CORRECTIV. 2015. CORRECTIV-Schulung: Journalistisch Arbeiten-Was Ist Ein Journalist.

Disponível em: <https://www.youtube.com/watch?v=DnwtJyFT7JQ>. Acesso em: 26 out. 2017. 
GANDOUR, Ricardo. Um Novo Ecossistema Informativo: como a fragmentação digital está moldando a forma pela qual produzimos e consumimos notícias. The Knight Center for Journalism in the Americas, 2016. Disponível em: $<$ https://knightcenter.utexas.edu/books/NewInfoEnvironmentPortugueseLink.pdf $>$.Aces so em: 17 jun. 2017.

GARCÍA, Xosé Lopez. Ciberperiodismo em la proximidad. Sevilha, Salamanca, Zamora, ES: Comunicación Social, 2008.

GARROSSINI, Fávaro et all (eds.). Comunicación y ciudad- La mediación social en la nueva cultura urbana. 1 out. 2016. Disponível em: $<$ http://www.gedisa.com/ficha.aspx?cod=500454\&titulo=Comunicaci\%C3\%B3nyciudad\#.V_C-kfkrJD>. Acesso em: 1 out. 2016.

GILLMOR, Dan. Nós, os media. Lisboa: Presença II, 2005.

GILLMOR, Dan. Where Did "Citizen Journalist" Come From?, 2008. Disponível em: $<$ http://citmedia.org/blog/2008/07/14/where-did-citizen-journalist-come-from/>. Acesso em: 28 nov. 2016.

HOHLFELDT, Antônio. Os Estudos sobre a Hipótese de Agendamento. Revista Famecos, no 7, pag. 42 - 51. Porto Alegre, nov. 1997.

JONES, Alan. Hyper-local media steps up as newspaper industry declines. The Guardian, Inglaterra, 21 jul. 2014. Disponível em: <https://www.theguardian.com/publicleadersnetwork/2014/jul/21/newspaper-industry-declines-hyper-local-media>. Acesso em: 17 jun. 2017.

LÉVY, Pierre. As Tecnologias da Inteligência - O futuro do pensamento na era da informática. (1990). São Paulo: Editora 34, 2006.

LIMA JÚNIOR, Walter Teixeira. Dispositivos móveis e APIs na construção do Jornalismo Hiperlocal. 2016. Disponível em: <http://seer.ufrgs.br/index.php/intexto/article/view/53096>. Acesso em: 22 maio 2017.

LIPPMANN, Walter. Opinião Pública. São Paulo: Ed. Vozes, 2010.

LUGANO, Giuseppe (2008). Mobile social networking in theory and practice. First Monday, Vol. 13, n. 11. Disponível em: 〈http://firstmonday.org>. Acesso em: 10 abr. 2019.

MACHADO, Elias. O ciberespaço como fonte para os jornalistas. 2003. Disponível em: <http://bocc.unisinos.br/pag/machado-elias-ciberespaco-jornalistas.pdf >. Acesso em: 25 mar. 2016.

MARTINS, Luiz. Sociedade, esfera pública e agendamento. In: BENETTI, Márcia; LAGO, Cláudia. Metodologia de Pesquisa em Jornalismo. Petrópolis: Vozes, 2007.

McCOMBS, Maxwell; SHAW, Donald L. The agenda-setting function of mass media. Public Opinion Quarterly, 1972.

MORAES, Francisco Munhoz; LEAL, Zelia Adghirni. 2011. Jornalismo e democracia: o papel do mediador. Disponível em: <http://www.compos.org.br/seer/index.php/ecompos/article/viewFile/642/520>. Acesso em: 29 out. 2017. 
MORETZSOHN, Sylvia. O “Jornalismo Cidadão" e o Mito da Tecnologia Redentora. Universidade Federal Fluminense, Brasil Comunicação e Sociedade, vol. 9-10, 2006, pp. 6381 Disponível em: 〈https://bjr.sbpjor.org.br/bjr/article/view/751/571>. Acesso em: 28 out. 2016.

NOELLE-NEUMANN, Elisabeth. La espiral del silencio. Paidós, 1995.

O'REILLY, Tim. "What Is Web 2.0"? Design Patterns and Business Models for the Next Generation of Software. (2005). O'Reilly Publishing. Disponível em:<http://www.oreillynet.com/pub/a/oreilly/tim/articles/pubmod.html>. Acesso em: 19 ago. 2015.

PRADO, Magaly. Webjornalismo. Rio de Janeiro: LTC/GEN, 2011.

PRADO, Magaly. Ciberativismo e Noticiário: da mídia torpedista às redes sociais. Rio de Janeiro. Ed. Alta Books, 2015.

PRADO, Magaly. As novas ferramentas necessárias ao exercício do jornalismo no mutante mercado impregnado pelas tecnologias digitais. 2015-2016 (no prelo).

RADCLIFFE, Damian. Here and Now: UK Hyperlocal Media Today. Nesta. Reino Unido, Londres: 2012.

ROSSITER, Ned. Organized networks: media theory, creative labour, new instit utions. Amsterdam: NAi Publishers, Rotterdam and the Institute of Network Cultures, 2006.

SANTAELLA, Lucia; LEMOS, Renata. Redes sociais digitais: a cognição conectiva do Twitter. São Paulo: Paulus, 2010.

SANTAELLA, Lucia. Comunicação Ubíqua. Repercussões na cultura e na educação. São Paulo: Paulus, 2013.

SANTOS, Milton et al. O Papel Ativo da Geografia: Um Manifesto, XII Encontro Nacional de Geógrafos. Florianópolis, 2000.

SHAW, Donald L. and McCOMBS, Maxwell E. The Emergence of American political issues: The Agenda-setting function of the Press, Saint Paul, Minnesotta, West Publishing Co. 1977.

SHIRKY, Clay. A Cultura da Participação - Criatividade e Generosidade no Mundo Conectado, Rio de Janeiro: Zahar, 2011.

SORJ, Bernardo. Meios de comunicação edemocracia: para além doconfronto entre governos eempresas. Working Paper, n. 20, jul. 2011. Disponível em: <http://www.plataformademocratica.org/Arquivos/Plataforma_Democratica_Working_ Paper_20_Portugues.pdf>. Acesso em: 17 jun. 2017.

TRAQUINA, Nelson. O paradigma da agenda-setting: Redescoberta do poder do ornalismo. Revista Comunicação e Linguagens. Lisboa: 1995.

TEWKSBURY, David; RITTENBERG, Jason. News on the internet - Information and Citizenship in the 21st Century. Oxford University Press, 2012.

WALDMAN, Steven. The information needs of Communities - the changing media landscape in a broadband age. Nonprofit News Websites. Jun 2011. Disponível em: < https://books.google.com.br/books?id=bLulzihSxPEC\&lpg=PA188\&dq=Some\%20sign ificant $\% 20$ national $\% 20$ efforts $\% 20$ to $\% 20$ sustain $\% 20$ journalism $\% 20$ also $\% 20$ have $\% 20$ be 
en\%20set \%20up\%20as\%20nonprofits\&hl=pt-BR\&pg=PP1\#v=onepage \&q\&f=true>. Acesso em: 17 jun. 2017.

WOLF, Mauro. Teorias da Comunicação, Lisboa: Presença,1992.

Data de Recebimento: 18/08/2018

Data de Aprovação: 22/04/201 9 


\section{Para citar essa obra:}

PRADO, Magaly; ALEXANDRI, Adrian. Um site como ferramenta In: RUA [online]. Volume 25, número 1 - Ahead of Print - e-ISSN 2179-9911 - junho/2019. Consultada no Portal Labeurb - Revista do Laboratório de Estudos Urbanos do Núcleo de Desenvolvimento da Criatividade. http://www.labeurb.unicamp.br/rua/

Capa: Figura 2: Print de parte da home do site goncalvesnomapa.com.br

Laboratório de Estudos Urbanos - LABEURB

Núcleo de Desenvolvimento da Criatividade - NUDECRI

Universidade Estadual de Campinas - UNICAMP

http://www.labeurb.unicamp.br/

Endereço:

LABEURB - LABORATÓRIO DE ESTUDOS URBANOS

UNICAMP/COCEN / NUDECRI

CAIXA POSTAL 6166

Campinas/SP - Brasil

CEP 13083-892

Fone/ Fax: (19) 3521-7900

Contato: http://www.labeurb.unicamp.br/contato 